\title{
A Simple Scheme for Modeling Irrigation Water Requirements at the Regional Scale Applied to an Alpine River Catchment
}

\author{
Pascalle C. Smith *, Pierluigi Calanca and Jürg Fuhrer \\ Air Pollution and Climate Group, Agroscope Research Station, Reckenholzstrasse 191, \\ CH-8046 Zürich, Switzerland; E-Mails: pierluigi.calanca@art.admin.ch (P.C.); \\ juerg.fuhrer@art.admin.ch (J.F.) \\ * Author to whom correspondence should be addressed; E-Mail: pascalle.smith@art.admin.ch; \\ Tel.: +41-44-377-7516; Fax: +41-44-377-7201.
}

Received: 11 September 2012; in revised form: 31 October 2012 / Accepted: 1 November 2012 / Published: 7 November 2012

\begin{abstract}
This paper presents a simple approach for estimating the spatial and temporal variability of seasonal net irrigation water requirement (IWR) at the catchment scale, based on gridded land use, soil and daily weather data at $500 \times 500 \mathrm{~m}$ resolution. In this approach, IWR is expressed as a bounded, linear function of the atmospheric water budget, whereby the latter is defined as the difference between seasonal precipitation and reference evapotranspiration. To account for the effects of soil and crop properties on the soil water balance, the coefficients of the linear relation are expressed as a function of the soil water holding capacity and the so-called crop coefficient. The 12 parameters defining the relation were estimated with good coefficients of determination from a systematic analysis of simulations performed at daily time step with a FAO-type point-scale model for five climatically contrasted sites around the River Rhone and for combinations of six crop and ten soil types. The simple scheme was found to reproduce well results obtained with the daily model at six additional verification sites. We applied the simple scheme to the assessment of irrigation requirements in the whole Swiss Rhone catchment. The results suggest seasonal requirements of $32 \times 10^{6} \mathrm{~m}^{3}$ per year on average over 1981-2009, half of which at altitudes above $1500 \mathrm{~m}$. They also disclose a positive trend in the intensity of extreme events over the study period, with an estimated total IWR of $55 \times 10^{6} \mathrm{~m}^{3}$ in 2009 , and indicate a $45 \%$ increase in water demand of grasslands during the 2003 European heat wave in the driest area of the studied catchment. In view of its simplicity, the approach can
\end{abstract}


be extended to other applications, including assessments of the impacts of climate and land-use change.

Keywords: Swiss Rhone catchment; agriculture; irrigation; climate; statistical modeling

\section{Introduction}

Water scarcity is considered, along with climate change, as one of the most pressing environmental issues of the 21 st century [1]. Agriculture is greatly concerned with water shortage, and in areas characterized by arid or semi-arid climates, irrigation is often the only option to secure productivity. Currently, irrigation is practiced on less than one fourth of the cropping area but it supports about $50 \%$ of the world food production. About $67 \%$ of the global water withdrawal is related to agricultural production, and $87 \%$ of the consumptive water is for irrigation purposes [2].

In view of an ever growing world population and projected shifts in precipitation patterns, which are likely to entail an increasing incidence of droughts in continental areas, it is expected that irrigation demand will increase in the future $[3,4]$. Clearly, only a judicious choice of irrigation strategies, based on quantitative estimates of the water requirements, will allow sustainable use of water resources. Unfortunately, for many countries and regions of the world, even the extent of today's irrigated areas and water use is poorly known.

To fill this gap, various initiatives have been put into action in recent years to estimate irrigation water use with the help of statistical tools and simulation models. Outcomes of these initiatives are e.g., the Global Irrigated Area Map [5], the Global Map of Irrigated Areas (GMIA) [6], the European Irrigation Map (EIM) [3] the global assessment of irrigation requirements [7] and the regional assessment of IWR in Europe (IWRE) [8]. While these products represent significant advances in the appraisal of water needs at the global or continental scale, their utility for planning purposes and in support of the adaptation process at the local to regional scale is still limited $[3,7,8]$. This is particularly the case in mountain areas, where due to complex topographic and rainfall patterns, along with a heterogeneous distribution of soils, vegetation types and agricultural practices, better resolved information is required. Complex distributed hydrological models can be used at this scale, although their high data demand is often difficult to meet.

Given these practical limitations of large-scale and complex hydrological models, the goal of the present work was to develop a simple modeling tool for quantifying the net irrigation water requirement, IWR, at the catchment scale with high spatial resolution. Net IWR is defined as the amount of water needed to reach an optimum or pre-defined level of crop productivity, without considering the efficiency of the water application system [7].

The proposed modeling approach relates seasonal net IWR to an integral measure of the atmospheric water budget, taking into account soil and crop characteristics. For the development, calibration and verification of this relation, an algorithm for computing crop and soil specific irrigation water requirements at the local scale and daily time step was needed. We relied on the methodology of the Food and Agriculture Organization of the United Nations (FAO) [9], but simulated dynamically growing season length, leaf area index, and seasonal evolution of the crop coefficient. 
The proposed relation was used to assess IWR in the Swiss part of the Rhone catchment where grassland, cropland, orchards and vineyards dominate the non-forested landscape. The latter is one of the target areas of the EU-FP7 project ACQWA [10], which aims at using advanced modeling techniques to quantify the influence of climatic change on the major determinants of the water cycle in mountain regions at various temporal and spatial scales. Similar calculations were performed as part of a virtual water and footprint analysis in the driest mountain catchment of Canada, the Okanagan Basin, where fruit trees and grapevines are cultivated and the total irrigated area is comparable to that of the Swiss Rhone catchment [11].

The present study supplements a recent effort to quantify irrigation water demand in Switzerland on the basis of simulations with a distributed hydrological model [12]. In [12], the Rhone catchment was identified among six basins as the one exhibiting the largest inter-annual variability of irrigation depth (i.e., irrigation requirement per unit of irrigated area) for cropland, and highest median for both cropland and grassland. In 2006, a survey performed by the Federal Department of Agriculture [13] reported that the water used in this region represents the largest fraction of the $144 \times 10^{6} \mathrm{~m}^{3}$ water used per year in Swiss agriculture, and about half of the country's $550 \mathrm{~km}^{2}$ irrigated area.

\section{Study Region}

\subsection{Characteristics}

River Rhone originates from the Rhone glacier in Switzerland and reaches the Mediterranean Sea in South-eastern France. Of the total discharge of the river Rhone 41\% come from the Alps, which is disproportionally high relative to the areal proportion of the Alpine region [14]. The upper part of the catchment of the river Rhone, down to the lake of Geneva, is located in Switzerland and covers $5250 \mathrm{~km}^{2}$ of land. $11.5 \%$ of this part of the catchment area are currently glaciated, a proportion expected to reach nearly zero by the end of the century [15]. The contribution of glacier storage change to the August runoff over the last century was $>40 \%$ and nearly $80 \%$ in the extreme year 2003 [15]. The study region encompasses nearly the whole Canton of Valais (Figure 1). The topography is very heterogeneous, ranging in elevation from $372 \mathrm{~m}$ above sea level (a.s.1.) at the Lake of Geneva to $4634 \mathrm{~m}$ a.s.l. at the so-called 'Dufour-Spitze'. Annual temperature and precipitation exhibit strong vertical gradients as well as variations along the main valley axis. The climate is further characterized by high radiation and low levels of air humidity.

Compared to the $1000 \mathrm{~mm}$ of average annual precipitation recorded on the Swiss Plateau (1961-1990, [16]), annual precipitation amounts in the eastern part of the Rhone valley are low, hardly attaining $600 \mathrm{~mm}$ (e.g., station Visp, Figure 1). Of this, only about $250 \mathrm{~mm}$ fall between April and September (about $300 \mathrm{~mm}$ when considering the period 1981-2009, Table 1) when evaporative demand reaches $10 \mathrm{~mm} \mathrm{day}^{-1}$ during summer. Thus, the climate in the main agricultural area can be considered semi-arid.

About one fifth of the area $\left(980 \mathrm{~km}^{2}\right)$ is used for agriculture (Figure 1a), with grasslands and pasture representing by far the largest share $\left(833 \mathrm{~km}^{2}\right)$ [17]. The most important activities from an economic perspective are those related to the cultivation of special crops. Grapevine is grown on the South facing slopes along the Rhone to the East and West of Sion, whereas fruit trees are more 
protected from frost during critical phases on the North facing slopes and on the flat valley bottom [18]. Arable crops, such as maize, benefit from the deeper soils and a less dry climate in the area close the outlet of the catchment. Otherwise, soils are shallow, with a total water holding capacity (TAW) of less than $20 \mathrm{~mm}$ (Figure 1b).

Figure 1. (Top) Map of Switzerland showing the location of the Canton Valais, Rhone catchment and the five sites selected for the modeling tool calibration. Coordinates and acronyms of the latter are given in Table 1; (Bottom) (a) Agricultural land use type; (b) Water holding capacity of the soil (TAW).
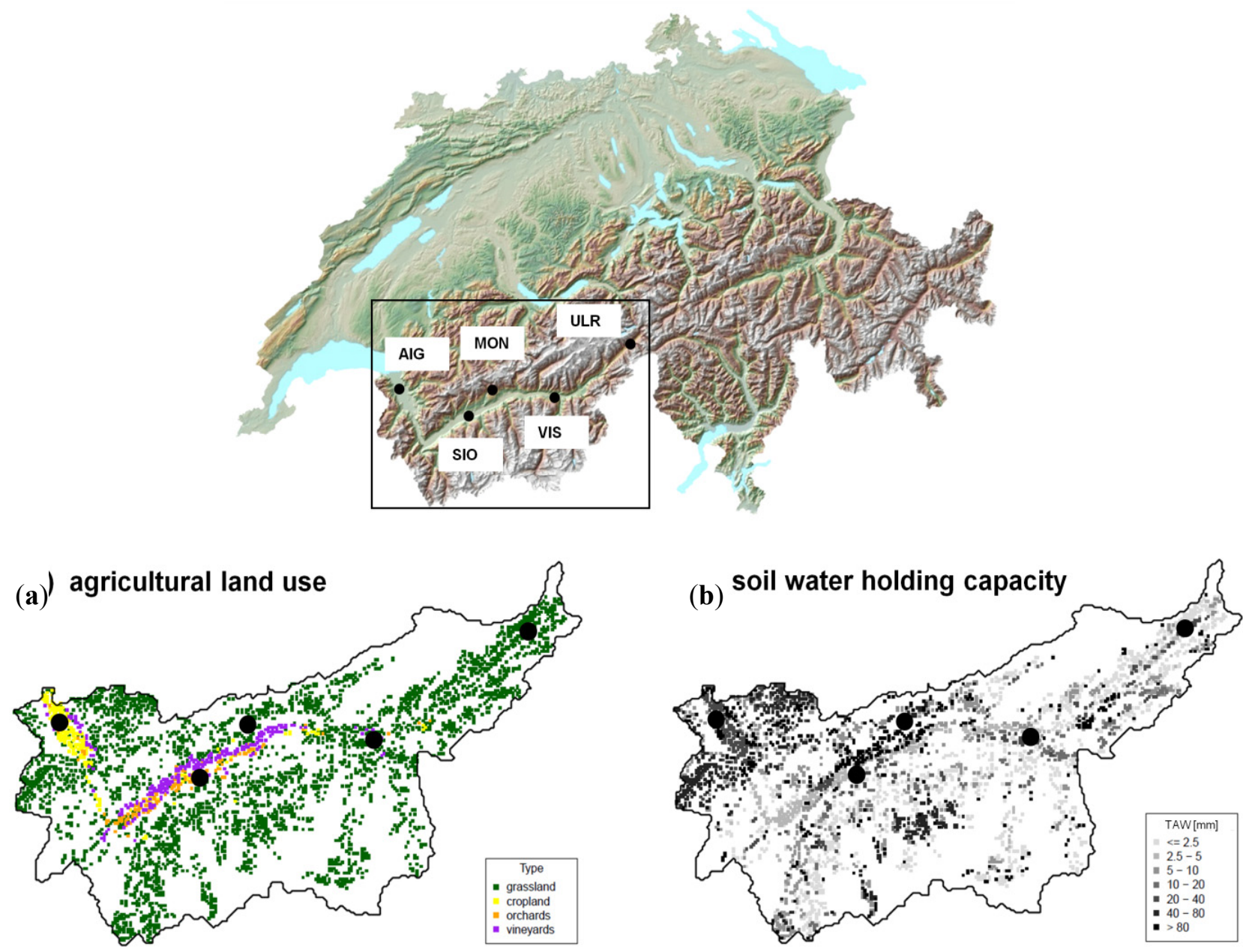

Table 1. Location, elevation and climate of the five sites selected for the estimation of the daily irrigation requirements over 1981-2009. The sites are: Aigle (AIG), Sion (SIO), Visp (VIS), Montana (MON) and Ulrichen (ULR) (see also Figure 1).

\begin{tabular}{ccccc}
\hline Site & Long./Lat. & $\begin{array}{c}\text { Elevation } \\
(\mathbf{m} \text { a.s.l.) }\end{array}$ & $\begin{array}{c}\text { April-September air } \\
\text { temperature }\left({ }^{\circ} \mathbf{C}\right)\end{array}$ & $\begin{array}{c}\text { April-September } \\
\text { precipitation }(\mathbf{m m})\end{array}$ \\
\hline AIG & $6.9 \mathrm{E} / 46.3 \mathrm{~N}$ & 382 & 14.8 & 747 \\
SIO & $7.3 \mathrm{E} / 46.2 \mathrm{~N}$ & 481 & 16.1 & 489 \\
VIS & $7.8 \mathrm{E} / 46.3 \mathrm{~N}$ & 639 & 15.4 & 314 \\
MON & $7.5 \mathrm{E} / 46.3 \mathrm{~N}$ & 1431 & 10.8 & 589 \\
ULR & $8.3 \mathrm{E} / 46.5 \mathrm{~N}$ & 1395 & 10.4 & 624 \\
\hline
\end{tabular}




\subsection{Current Irrigation Estimates}

Irrigation channels have been in place since the 13th century, mainly in the area between Sion and Visp, deviating streams to give pastures, fields, vineyards and orchards access to the locally missing water. While snow melt peaks in July, ice melt peaks in August, both contributing to the runoff [15]. The total amount of water withdrawn for irrigation has been estimated in [13] as $97 \times 10^{6} \mathrm{~m}^{3} \mathrm{yr}^{-1}$, of which $86.5 \times 10^{6} \mathrm{~m}^{3} \mathrm{yr}^{-1}$ are supplied to the fields through open channel systems.

The study area appears as a local irrigation hotspot in the GMIA [6], the EIM [3], and the IWRE [8]. The share of irrigated land as given in the GMIA is 5 to $35 \%$ for the area downstream of Sion, with a similar picture emerging from the IEM. IWR amount to $100-250 \mathrm{~mm} \mathrm{yr}^{-1}$ in the IWRE, which compares favorably with the $100 \mathrm{~mm} \mathrm{yr}^{-1}$ irrigation depth estimated by [12] for grasslands.

\section{Methods}

\subsection{Overall Approach}

Seasonal IWR at the catchment scale was inferred assuming a linear dependence upon the atmospheric water budget, whereby the latter represents the difference between precipitation and reference evapotranspiration. To establish the functional form of the relation, the following steps were required:

1. Computing daily irrigation requirements $\left(I W R_{\text {day }}\right)$ at the point scale for a selection of representative sites (Section 3.3). This was done by solving the soil water balance equation for the root zone and assuming that irrigation is required to avoid water stress whenever the actual root zone water depletion exceeds a pre-defined threshold;

2. Integrating $I W R_{d a y}$ over the growing season to obtain corresponding seasonal estimates (IWR). The growing season was defined according to the seasonal evolution of the crop coefficient, $K_{\mathfrak{c}}$, which was computed as function of the leaf-area index (Section 3.4);

3. Linking seasonal IWR to the atmospheric water budget through a statistical analysis of the results obtained in the previous step. It was found that the assumed linear relation could be generalized across soil and crop types provided that its parameters are expressed as a function of the soil water holding capacity and crop coefficient (Section 3.4).

\subsection{Weather, Land Use and Soil Data}

The weather data used were the same daily gridded fields for precipitation, air temperature, wind speed, vapor pressure, relative humidity, global radiation and sunshine duration as already employed in [12]. They were obtained through spatial interpolation of station data provided by the Swiss Federal Office of Meteorology and Climatology (MeteoSwiss). The interpolation procedure was based on a weighted combination of inverse-distance interpolation and altitude-dependent regression [19,20]. Before interpolation, precipitation data were error-corrected separately for snow and rain using specific correction factors [20].

Geospatial data used for meta-model application (i.e., upscaling, Section 4), including a digital elevation model, a digital land-use map and digital information concerning soil hydraulic characteristics were obtained from various sources identified by [12]. The 74 land-use categories originally 
defined in [17] were recombined into four categories (Figure 1a), the non-agricultural land being ignored given the focus on irrigation. All spatial data were mapped with a $500 \mathrm{~m} \times 500 \mathrm{~m}$ grid cell size.

\subsection{Point-Scale Estimation of Daily Irrigation Requirements}

Daily irrigation requirements were estimated as in [9] by considering the vertical water balance equation for the root zone. Assuming a single soil layer of constant thickness $Z_{r}$ and total water holding capacity in the root zone $T A W=\left(\Theta_{F C}-\Theta_{W P}\right) \cdot Z_{r}$, where $\theta_{F C}$ and $\theta_{W P}$ are volumetric water contents at field capacity and wilting point, respectively, the water budget equation can be written as:

$$
\frac{d}{d t}\left(D_{r}\right)=-P-R O-D P-I W R_{d a y}+E T_{a}
$$

where $D_{r}$ is the actual soil water depletion; $P$ the daily precipitation; $R O$ the surface runoff; $D P$ the deep percolation; $I W R_{d a y}$ the daily irrigation amount and $E T_{a}$ the actual evapotranspiration. In solving the balance Equation (1), neither rainfall interception, nor lateral water movements, water ponding at the surface, water storage as snow or capillary rise were considered. Infiltration capacity was defined as the difference between soil porosity and actual water content, and all precipitation in excess of the infiltration capacity was removed as surface runoff. Furthermore, all water content in excess of field capacity was removed as deep percolation. Initial soil moisture was set equal to field capacity.

Following Allen et al. [9], actual evapotranspiration $E T_{a}$ was computed as:

$$
E T_{a}=K_{s} \cdot K_{c} \cdot E T_{0}
$$

where $E T_{0}$ is the so-called reference evapotranspiration; $K_{c}$ the crop coefficient (which will be further described below); and $K_{s}$ a multiplicative factor accounting for the effects of water stress. According to Allen et al. [9]; $E T_{0}$ is defined as the evapotranspiration of a well-watered grass surface with an assumed height of $0.12 \mathrm{~m}$, a fixed surface resistance of $70 \mathrm{~s} \mathrm{~m}^{-1}$ and an albedo of 0.23 . It is computed by means of the Penman-Monteith equation, which reads:

$$
E T_{0}=\frac{\Delta\left(R_{n}-G\right)+\rho_{a} C_{p} \frac{\left(e_{s}-e_{a}\right)}{r_{a}}}{\Delta+\gamma\left(1+\frac{r_{s}}{r_{a}}\right)}
$$

where $R_{n}$ is the net radiation; $G$ the soil heat flux; $\left(e_{s}-e_{a}\right)$ represents the vapor pressure deficit of the air; $\rho_{a}$ is the mean air density at constant pressure; $C_{p}$ is the specific heat of the air; $\Delta$ represents the slope of the saturation vapor pressure temperature relationship; $\gamma$ is the psychrometric constant; and $r_{s}$ and $r_{a}$ are the (bulk) surface and aerodynamic resistances. The estimation of $r_{a}$ and $r_{s}$ for use in Equation (3) is detailed in [9], while $R_{n}$ was estimated from global radiation using the approach suggested by [21], and $G$ was set equal to 0 .

In Equation (2), the stress factor $K_{s}$ can be expressed in terms of $D_{r}$ as:

$$
K_{s}= \begin{cases}1 & \text { if }\left(T A W-D_{r}\right) \geq(1-p) \cdot T A W \\ \frac{T A W-D_{r}}{(1-p) \cdot T A W} & \text { otherwise }\end{cases}
$$


where $p$ is a crop-specific parameter depending on unstressed crop evapotranspiration $E T_{c}=K_{c} \cdot E T_{0}$ :

$$
p=p_{5}+0.04 \cdot\left(5-E T_{c}\right)
$$

where $p_{5}$ is a prescribed value of $p$ corresponding to an $E T_{c}$ of $5 \mathrm{~mm}$ day ${ }^{-1}$. Values of $p_{5}$ for cut and grazed grassland, maize, apple, apricot and grapevine are $0.55,0.60,0.55,0.50,0.50$ and 0.45 , respectively.

Given the daily soil moisture depletion, irrigation was assumed to be necessary whenever

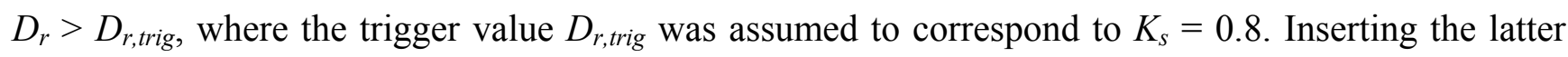
equality in Equation (4) gives:

$$
D_{r, \text { trig }}=(0.2+0.8 p) \cdot T A W
$$

For each irrigation event, the daily irrigation requirement $\left(I W R_{\text {day }}\right)$ was defined as the amount of water necessary to bring $K_{s}$ back to 1 . From Equation (4) this is can be calculated as:

$$
I W R_{\text {day }}= \begin{cases}p \cdot T A W-D_{r} & \text { if } D_{r}>D_{r, t r i g} \\ 0 & \text { otherwise }\end{cases}
$$

Simulations of daily irrigation requirements based on Equation (1) through Equation (7) were performed for five sites representing the range of elevation and climate characteristic of the catchment (Figure 1 and Table 1). Daily weather data covering 1981-2009 were extracted for each site from the gridded data described in Section 3.2.

To obtain $I W R_{\text {day }}$ for a wide spectrum of soil and crop conditions, the following soil and crop categories were considered:

- 10 values of the total water holding capacity ranging from 5 to $240 \mathrm{~mm}$;

- 6 crop categories, including cut grasslands and pastures, maize, apple, apricot and vineyards, each of which was defined through different setups of the crop coefficient.

For orchards (i.e., apple and apricot) and vineyards $K_{c}$ was prescribed identically for each year based on data published in [22,23], with resulting growing season mean $K_{c}$ of $0.82,0.51$ and 0.36 , for apple, apricot and vineyards, respectively. For these crops, we further assumed a fixed growing season length of 183 (apple and apricot) and 216 days (vineyards) (Table 2). A minimum $K_{c}$ of 0.15 was specified outside the growing season, as more than half of the orchards in the study region have a grass cover between rows [22].

For grassland and maize the crop coefficient $K_{c}$ was diagnosed from the daily leaf area index (LAI). To this aim specific simulations of crop growth were carried out with the grassland simulator PROGRASS [24] and the process-based crop model STICS [25]. The identified relation reads:

$$
K_{c}=\max \left\{0,[\ln (L A I+1)]^{0.4}\right\}
$$

where for maize $L A I$ can be expressed as a function of the growing degree days $(G D D)$ as:

$$
L A I= \begin{cases}0 & \text { if } G D D<500 \text { or } G D D \geq 2000 \\ 1 / 100 \cdot G D D-5.0 & \text { if } G D D \geq 500 \text { and } G D D<1100 \\ 6 & \text { if } G D D \geq 1100 \text { and } G D D<1650 \\ -6 / 350 \cdot G D D+34.5 & \text { if } G D D \geq 1650 \text { and } G D D<2000\end{cases}
$$


assuming a base temperature of $>6^{\circ} \mathrm{C}$ and setting the harvest date either corresponding to $G D D=2000{ }^{\circ} \mathrm{C} \mathrm{day}^{-1}$ or at latest on 1 November. For cut grasslands, we assumed a cutting regime with cuts taking places when $L A I=4 \mathrm{~m}^{2} \mathrm{~m}^{-2}$, but not before 1 May and no later than 1 November. Minimum $L A I$ was set as $L A I_{\min }=0.5 \mathrm{~m}^{2} \mathrm{~m}^{-2}$, and within each growing cycle, the daily increment $\triangle L A I$ was specified as,

$$
\Delta L A I= \begin{cases}0.008 \cdot\left(T_{a}-T_{B}\right) & \text { if } T_{a} \geq T_{B} \\ 0 & \text { otherwise }\end{cases}
$$

where $T_{a}$ is daily mean air temperature, $T_{B}=2.5{ }^{\circ} \mathrm{C}$ the corresponding base temperature, and initial $L A I$ was set to $0.5 \mathrm{~m}^{2} \mathrm{~m}^{-2}$. Pastures (grazed grasslands) were modeled in the same way as cut grassland but with a cutting threshold set to $L A I=2.5 \mathrm{~m}^{2} \mathrm{~m}^{-2}$.

\subsection{Seasonal Integration and Modeling of Seasonal Irrigation Requirements}

For all combinations of sites, soil water holding capacities and crops reference values of the seasonal IWR were obtained by integrating the daily irrigation requirements over the relevant growing season. Starting and ending dates of the effective growing season were specified for maize and grassland with respect to $K_{c}$ (Table 2), and computed for each year as the dates of the up- and downcrossing of the threshold corresponding to the arithmetic mean between minimum and maximum $K_{c}$ over the study period. This procedure provides more robust estimates than found e.g., with respect to the exceedance of temperature thresholds.

Table 2. Crop specific seasonal mean $K_{c}$ and growing season length based on simulations for 1981-2009 at the sites specified in Table 1.

\begin{tabular}{ccc}
\hline Crop type & Growing season mean Kc (-) & Growing season mean length (days) \\
\hline Grassland (cut or grazed) & 0.95 or 0.88 & 190 or 208 \\
Cropland (maize) & 1.09 & 122 \\
Orchards (apple or apricot) & 0.82 or 0.51 & both 183 \\
Vineyards & 0.36 & 216 \\
\hline
\end{tabular}

Preliminary data examination indicated that for a given soil and crop type seasonal IWR can be expressed as a bounded, linear function of the seasonal integral of the atmospheric water budget $\left(\left\langle P-E T_{0}\right\rangle\right)$, after scaling IWR estimates as well as $\left\langle P-E T_{0}\right\rangle$ to a common growing season length of 200 days. Indicating with $I W R_{200}$ and $\left\langle P-E T_{0}\right\rangle_{200}$ these scaled values, we have:

$$
I W R_{200}=\max \left\{\left[A \cdot\left\langle p-E T_{0}\right\rangle_{200}+b\right], I W R_{\min }\right\}
$$

This relation is illustrated in Figure 2 for cut grassland and $T A W=32.5 \mathrm{~mm}$. 
Figure 2. Relationship between seasonal $I W R_{200}$ and $\left\langle P-E T_{0}\right\rangle_{200}$. The plot is based on 29 years of simulated data for cut grassland with $T A W=32.5 \mathrm{~mm}$ at the sites given in Table 1 and shown in Figure 1. The line represents Equation (11), with the horizontal branch to the right indicating $I W R_{\min }$. A similar relationship was found for all other combinations of crops and soils.

grassland, TAW $=32.5 \mathrm{~mm}$

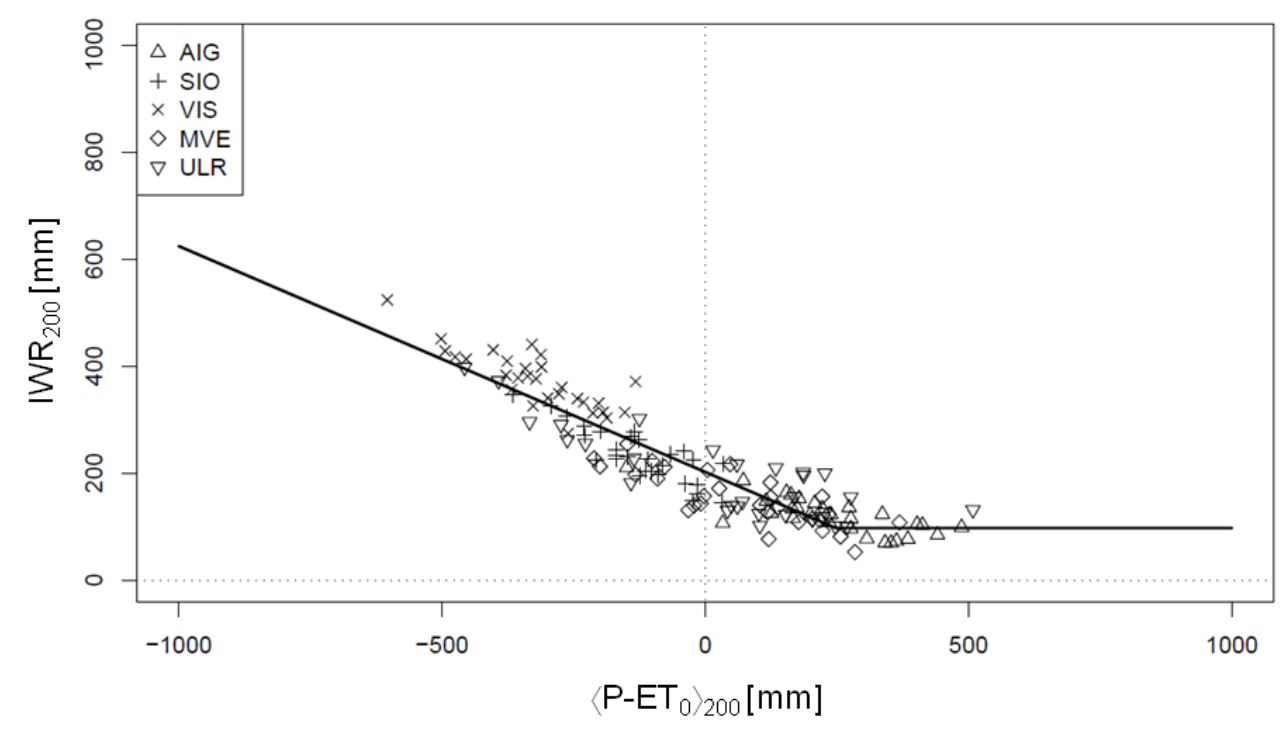

Examination of similar plots for all combinations of crops and soils further suggested that Equation (11) can be generalized provided that $A, B$ and $I W R_{\min }$ are expressed as a function of $T A W$ and $K_{c}$ :

$$
\left\{\begin{aligned}
A & =c \cdot \ln (T A W)+d \\
B & =e \cdot \ln (T A W)+f \\
I W R_{\min } & =p \cdot \ln (T A W)+q
\end{aligned}\right.
$$

with:

$$
\left\{\begin{array}{l}
c=g \cdot K_{c}+h \\
d=i \cdot K_{c}+j \\
e=k \cdot K_{c}+l \\
f=m \cdot K_{c}+n \\
p=r \cdot K_{c}+s \\
q=t \cdot K_{c}+u
\end{array}\right.
$$

The only exceptions we found, for which the model given by Equation (11) with Equations $(12,13)$ failed to provide an adequate description of seasonal IWR, were shallow soils, viz. soils with a total holding capacity of $T A W<5 \mathrm{~mm}$ for vineyards, $T A W<15 \mathrm{~mm}$ for maize, and $T A W<9 \mathrm{~mm}$ for all other crops. Equations $(12,13)$ are illustrated in Figure 3. 
Figure 3. Modulation of the generic relationship between $I W R_{200}$ and $\left\langle P-E T_{0}\right\rangle_{200}$ by soil water holding capacity (a) $T A W$; and crop type (b) $K_{c}$. The continuous lines represent Equation (12) in the left panel and Equation (13) in the right panel.
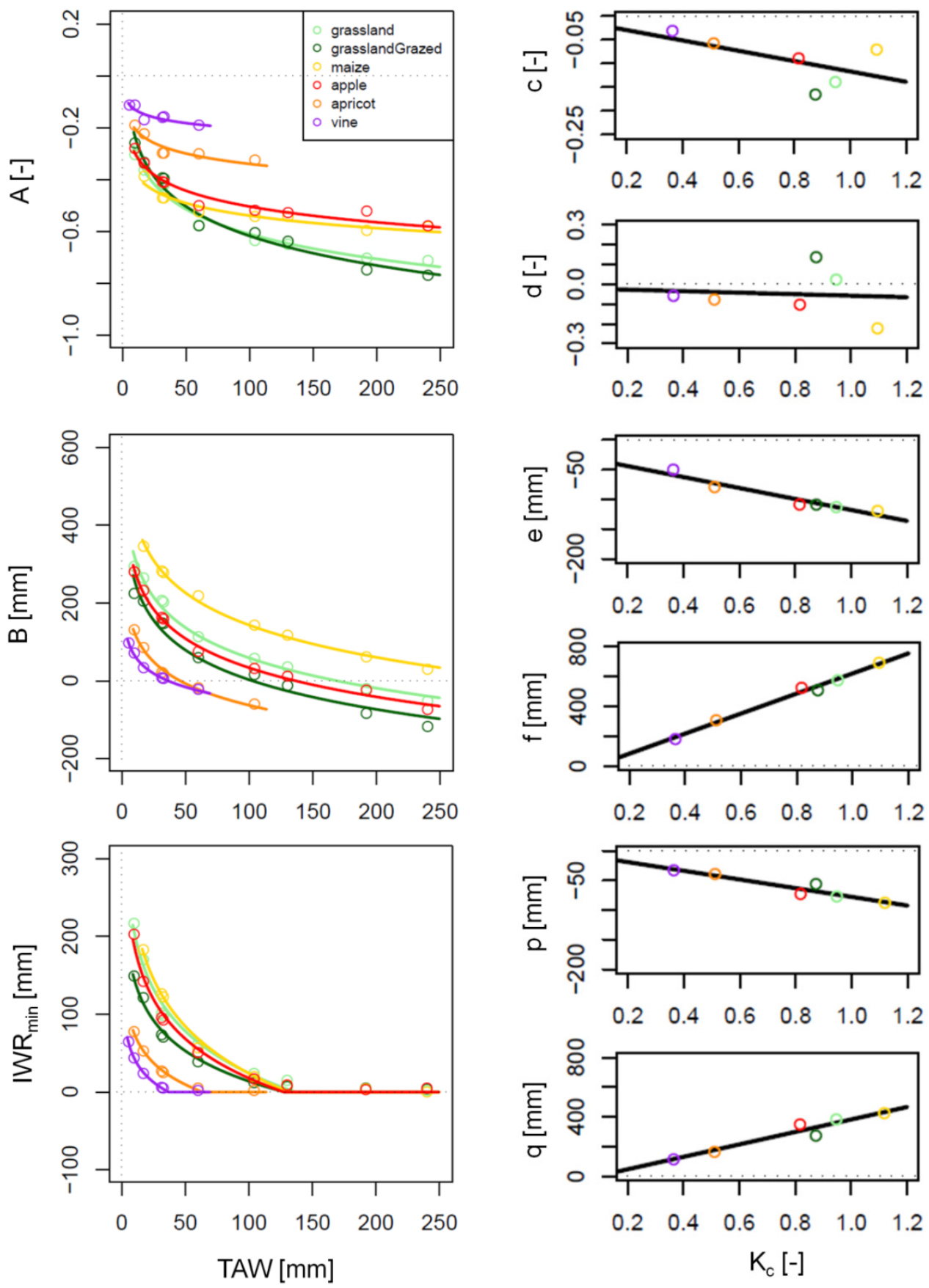

(a)

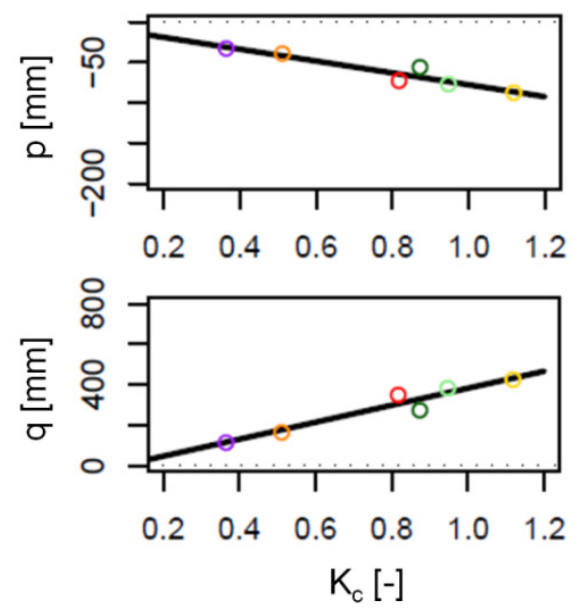

(b)

\section{Results}

\subsection{Model Calibration and Assessment}

The values of the 12 model parameters $g$ to $u$ were obtained by stepwise fitting Equations (11-13) for all combinations of crop and soil types. Resulting parameter values were: $g=-0.109 ; h=-0.008$; $i=-0.038 ; j=-0.019 ; k=-92.0 \mathrm{~mm} ; l=-25.5 \mathrm{~mm} ; m=676.0 \mathrm{~mm}, n=-54.2 \mathrm{~mm} ; r=-73.0 \mathrm{~mm}$; 
$s=-4.5 \mathrm{~mm} ; t=420 \mathrm{~mm}$ and $u=-38.2 \mathrm{~mm}$. It should be noted that for each of the three steps involved in fitting Equations (11-13) the coefficient of determination, $\mathrm{R}^{2}$, was high, varying between 0.52 and 0.87 for Equation (11) (and equal to 0.84 in the example of Figure 2), between 0.80 and 1 for Equation (12) and between 0.90 and 0.99 for Equation (13).

After parameter fitting, we verified Equation (11) through Equation (13) by comparing estimates of the seasonal IWR with more detailed results from the point-scale daily model for six additional sites (one per crop type) representing contrasting climate and soil characteristics. Again, meteorological data needed to evaluate seasonal $P$ and $E T_{0}$ were extracted from the gridded data described in Section 3.2. Growing season length and seasonal mean of daily $K_{c}$ was computed according to Equations (8-10), and $I W R_{200}$ was eventually rescaled to provide IWR.

With respect to the model assessment, the overall agreement was very good (not shown), with performance statistics computed over the ensemble of verification runs given as $R^{2}=0.64$, root-mean square error $R M S E=41 \mathrm{~mm}$ and Bias $=+2 \mathrm{~mm}$.

Good model performance was also found with respect to year-to-year variations in IWR. As an illustrative example for grasslands, Figure 4 shows a comparison of results obtained from the daily model, on the one hand, and Equations (11-13), on the other hand, at two calibration sites (Aigle humid, and Visp dry) on a shallow soil and two verification sites on deeper soils, located in side Valleys in the South of the Rhone catchment, respectively.

Figure 4. Time series of seasonal IWR for grassland at Aigle (a); Visp (b); and two of the verification sites near Evolène $(\mathbf{c})$ and Zermatt $(\mathbf{d})$. Thin lines represent results obtained with the daily point-scale model, and thick lines display the estimate given by Equations (11-13).
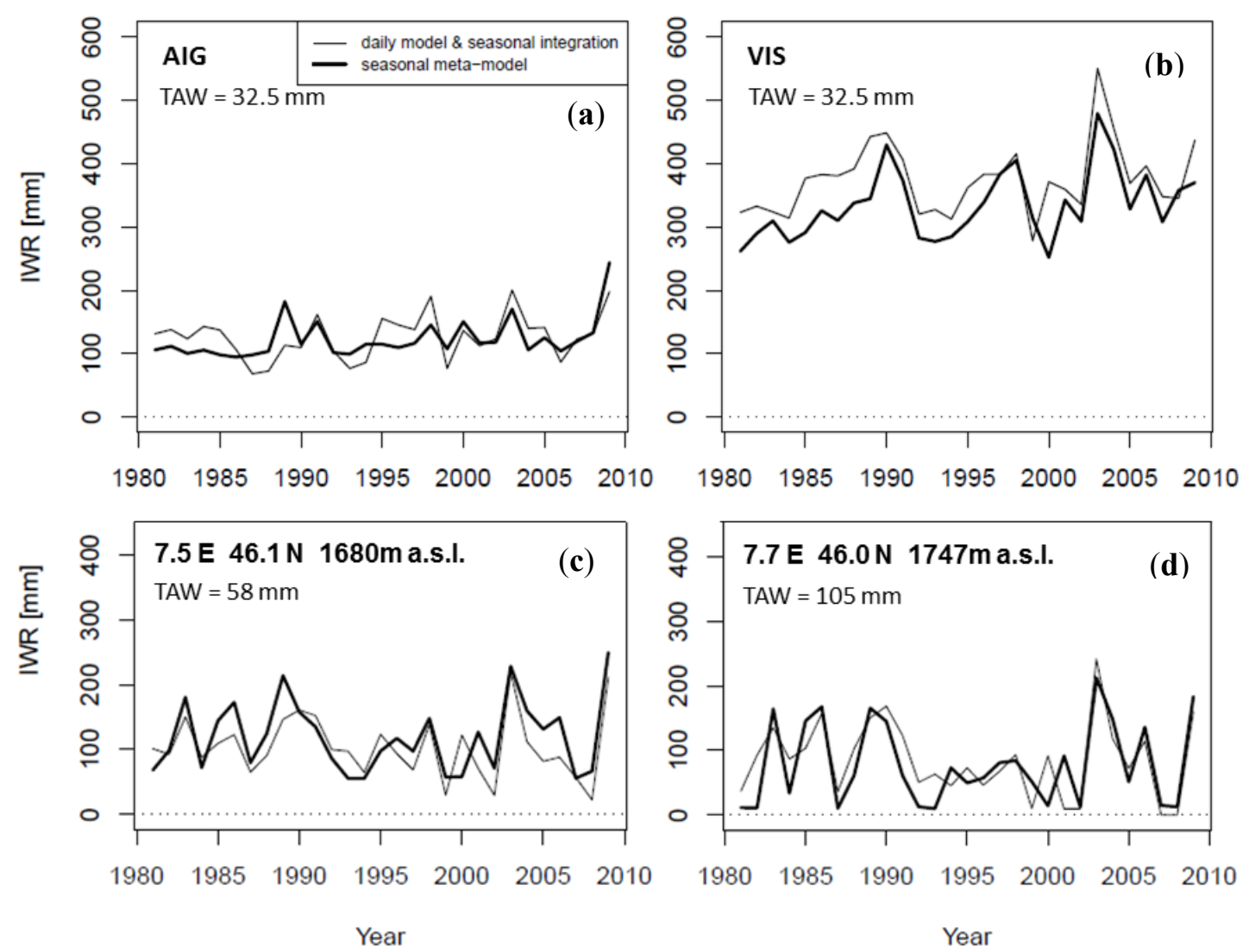
As seen in this figure, Equations (11-13) were able not only to correctly reproduce differences between crops, soils and sites, but also to provide reliable estimates of seasonal IWR for extreme years. For Visp, average (1981-2009) IWR obtained from Equations (11-13) was $334 \mathrm{~mm}$, as compared to $375 \mathrm{~mm}$ obtained with daily simulations (Figure 4b), and for 2003 as the year with the highest atmospheric demand, values of IWR at Visp were 479 and $550 \mathrm{~mm}$, respectively, representing relative anomalies of $+43 \%$ and $+46 \%$. Performance statistics relative to the comparison of the two time series at Visp were $R^{2}=0.69, R M S E=12 \%$ and Bias $=-11 \%$ relative to the average of $375 \mathrm{~mm}$.

\subsection{Spatial Patterns of Mean and Extreme IWR}

For the estimation of IWR from Equation (11) to Equation (13) at the catchment scale, the gridded soil and land use data described in Section 3.2 were used. Start and end of the growing season and seasonal mean $K_{c}$ were computed using the procedure outlined in Section 3.3.

In Figure 5, spatial patterns of average IWR for 1981-2009 are plotted along with the spatial distribution of $\left\langle P-E T_{0}\right\rangle$ and the corresponding anomalies for 2003. Positive values of the atmospheric water budget were obtained for the uppermost and lowermost parts of the catchment, reaching over $200 \mathrm{~mm}$ per season. Negative values were found in the central part between Sion and Visp, as well as in lateral valleys on the south side of the main valley. Negative seasonal atmospheric budgets varied typically from 0 to $-200 \mathrm{~mm}$, with a maximum of $-400 \mathrm{~mm}$ in the surroundings of Visp (Figure 5a).

Figure 5. Spatial distribution of (a) the average atmospheric water budget $\left\langle P-E T_{0}\right\rangle$ for 1981-2009; (b) the corresponding anomaly for 2003; (c) average seasonal IWR for 1981-2009; and (d) the corresponding anomaly for 2003. Points indicate sites described in Table 1 and Figure 1.
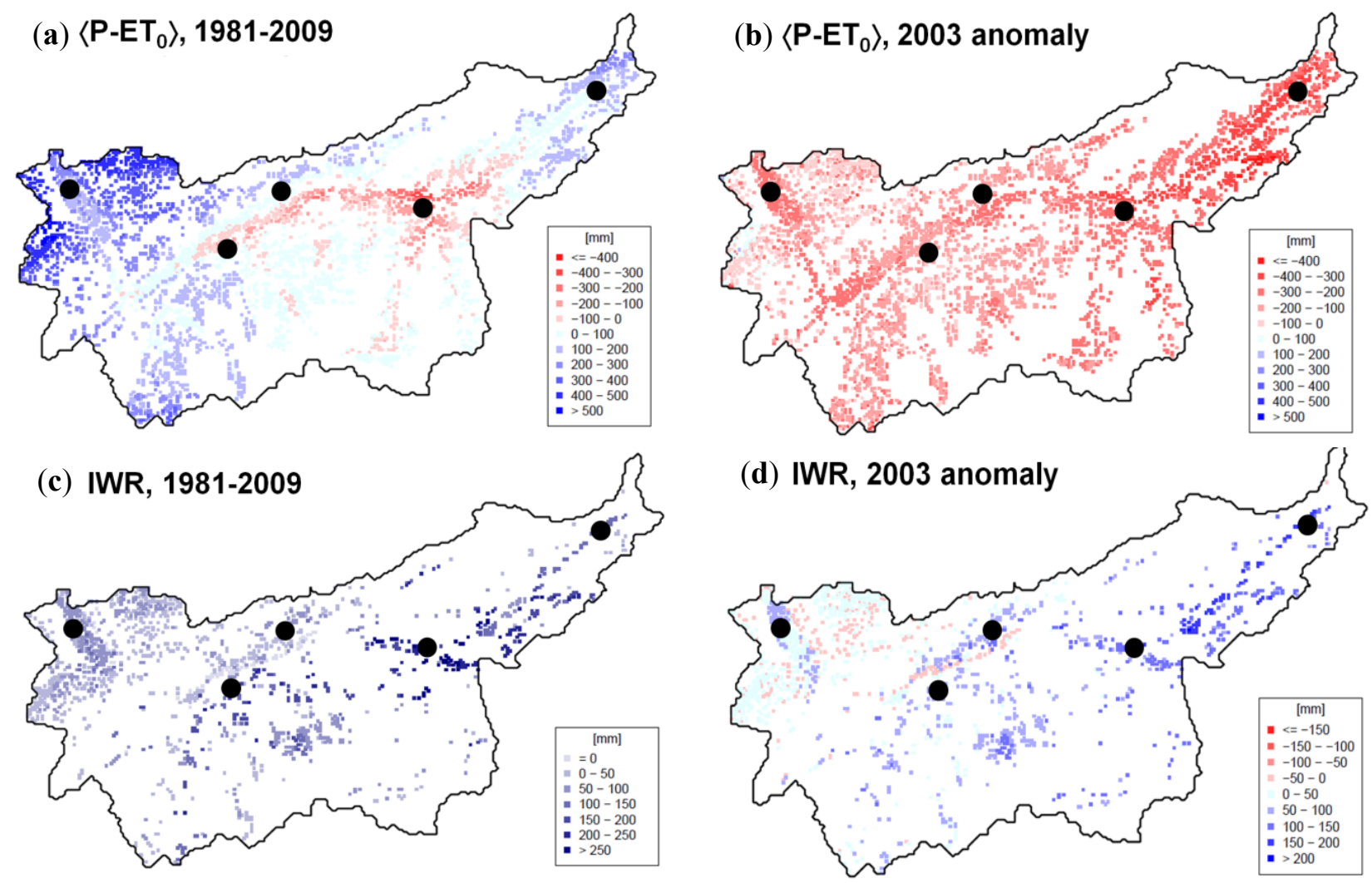
Seasonal IWR ranged from 0 to $50 \mathrm{~mm}$ in the area around Aigle and at higher elevations, and reached more than $250 \mathrm{~mm}$ in the Visp region (Figure $5 \mathrm{c}$ ). For $59 \%$ of the agricultural area, soil water holding capacities were smaller than $5 \mathrm{~mm}$ (vineyards), $15 \mathrm{~mm}$ (maize) and $9 \mathrm{~mm}$ (all other crops). Corresponding grid points were thus excluded from the analysis. The remaining $41 \%$ were assumed to represent the area that potentially requires irrigation. This area may include points with IWR of $0 \mathrm{~mm}$ depending on climate variability and related crop-specific evaporative demand.

In 2003, a negative precipitation anomaly was already recorded during winter and spring, and again in July [10], resulting in a strong negative anomaly of the seasonal atmospheric water budget throughout the study region (Figure 5b) with values between -200 and more than $-400 \mathrm{~mm}$. Corresponding seasonal IWR exceeded $200 \mathrm{~mm}$ upstream and 50-100 $\mathrm{mm}$ near the outlet of the catchment, i.e., below Aigle (Figure 5d).

\subsection{Time Series of IWR Aggregated over the Catchment}

Aggregated values of IWR across the entire catchment varied between 22 and $55 \times 10^{6} \mathrm{~m}^{3}$, approximating $32 \times 10^{6} \mathrm{~m}^{3}$ on average for the period 1981-2009 (Figure 6a).

Figure 6. Stacked area charts of (a) total IWR during 1981-2009 for different elevation ranges; and (b) of the percentage of the total agricultural area that required different irrigation intensities. The $41 \%$ line indicates the potentially irrigated area.
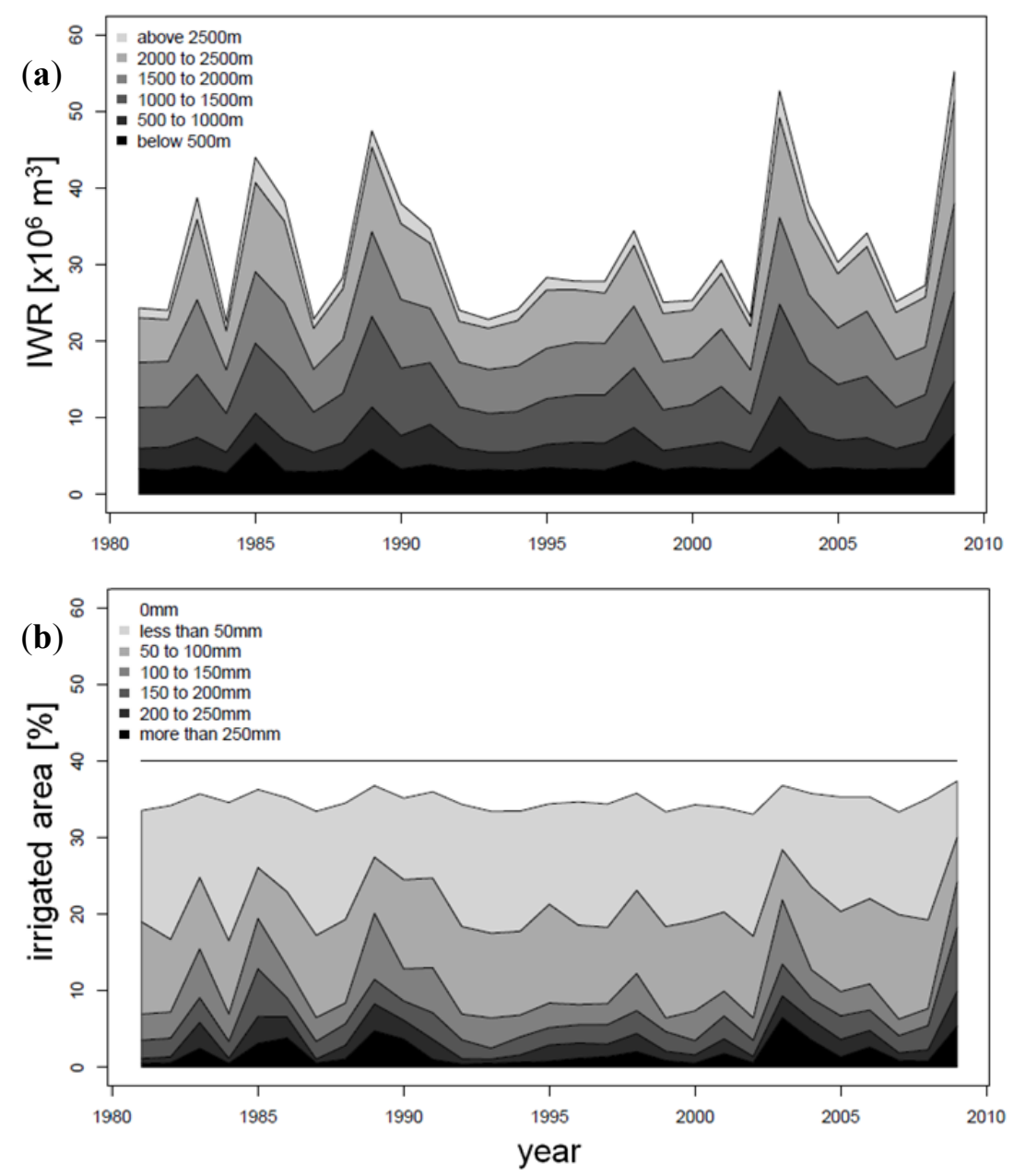
In 8 out of 29 years, IWR was below $25 \times 10^{6} \mathrm{~m}^{3}$, but exceeded $40 \times 10^{6} \mathrm{~m}^{3}$ in 4 years. IWR was particularly high toward the end of the time period considered, reaching $53 \times 10^{6} \mathrm{~m}^{3}$ in 2003 and $55 \times 10^{6} \mathrm{~m}^{3}$ in 2009. On average, half of total IWR was allocated to areas above $1500 \mathrm{~m}$ altitude. The relative anomaly in IWR for 2003 is $65 \%$ at catchment scale including the effect of a $6 \%$ increase in irrigated area.

Half of the area that would potentially require irrigation (that is $20 \%$ of total agricultural area, Figure 6b) received less than $50 \mathrm{~mm}$ per season and an additional quarter of the area needed between 50 and $100 \mathrm{~mm}$ per season. Only an estimated $5 \%$ of the total agricultural area appeared to require, on average, more than $200 \mathrm{~mm}$ per season, but this fraction doubled in extreme years (1989, 2003 and 2009).

\section{Discussion}

A simple modeling scheme is presented for estimating crop and soil specific net seasonal IWR from the atmospheric water budget. The proposed model is able to reproduce results obtained from a more detailed analysis at the daily step. Applied to the Swiss part of the Rhone catchment, the method gives a catchment-scale IWR of $32 \times 10^{6} \mathrm{~m}^{3} \mathrm{yr}^{-1}$. Using a distributed hydrological model, a requirement of $3.6 \times 10^{6} \mathrm{~m}^{3} \mathrm{yr}^{-1}$ to $4.2 \times 10^{6} \mathrm{~m}^{3} \mathrm{yr}^{-1}$ was calculated in an earlier study for the central part of the basin $\left(1574 \mathrm{~km}^{2}\right)$ [12]. Extrapolated to the entire catchment this amounts to $10-15 \times 10^{6} \mathrm{~m}^{3} \mathrm{yr}^{-1}$ a factor of two less than estimated in our work. While these earlier figures are based on the application of a hydrological model that describes in more detail the vertical water balance and accounts for snow cover, they also reflect the assumption of a static prescription of crop properties. The advance made with the model presented our study is clearly the consideration of seasonal vegetation dynamics.

The estimate of $97 \times 10^{6} \mathrm{~m}^{3} \mathrm{yr}^{-1}$ by the cantonal authorities, based on an analysis of questionnaires distributed to farmers in the study area [13], is clearly higher than the estimate produced here. However, the figure represents bulk water abstraction through irrigation channels (ignoring the inefficiency of the channels themselves which account for $90 \%$ of the types of access to water), and it thus includes water loss through evaporation, runoff and percolation of the irrigation water applied. In contrast, our estimate is based on the theoretical amount needed to satisfy crop water demand with $100 \%$ efficiency. Considering an overall efficiency of $<50 \%$ in irrigation with open channels [13,26-28], the aggregated average IWR obtained here is in reasonable agreement with the survey data. On average, in the Okanagan Basin, the driest in Canada, the irrigation water requirement (accounting as in [13] for a non $100 \%$ efficiency) is higher than in the Rhone catchment, amounting between 100 and $140 \times 10^{6} \mathrm{~m}^{3}$ per year (for a wet and a dry year respectively), for an irrigated area of $200 \mathrm{~km}^{2}[11]$. Both basins however have in common the dominance of fodder crops in terms of irrigated area and amounts.

Concerning spatial distribution, we found the highest values of irrigation water requirement in the area upstream of Sion. This is in contrast with the picture delivered by GMIA [6] and EIM [3], but in agreement with results from [13], stressing the importance of studies at the local scale for developing targeted information for planners, authorities and end-users.

Of the $980 \mathrm{~km}^{2}$ agricultural area within the basin, about $86 \%$ are classified as grasslands. These are meadows and pastures that, unlike cropland and orchards, cover land with less favorable growing conditions across a wide range of elevations. Of the potentially irrigated areas, grasslands represent 
only $80 \%$ because more shallow soils predominantly located at higher elevations were excluded. Of the remaining potentially irrigated grasslands, still $63 \%$ are found above $1500 \mathrm{~m}$ a.s.1. and thus account for half of the estimated total irrigated area. The proportion is the same in terms of surface area and IWR amounts, which indicates that the overall irrigation depth is similar below and above $1500 \mathrm{~m}$ a.s.l. This is surprising as lower irrigation intensity were expected at higher elevations given the more favorable atmospheric water budget. In practice, however, the latter is compensated for by the fact that soils are shallower and is grassland more sensitive to water deficiency than grapevine or maize grown on the deep soils near the outlet of the catchment.

According to a questionnaire distributed to cantonal administrations [13], the Swiss Federal Office of Agriculture estimated that about $30 \%$ of the total agricultural land area in the Valais is currently equipped for irrigation. In our analysis the fraction of area potentially requiring irrigation is $40 \%$, and thus higher than the estimate based on the survey. The difference can be explained by the fact that irrigation is not allowed above $1400 \mathrm{~m}$ and $1900 \mathrm{~m}$ a.s.1. on northern and southern slopes, respectively.

Looking at anomalies in individual years relative to the estimated average IWR, it is noted that years characterized by extremely dry conditions were not evenly spread over the time period considered. Four of these years appeared between 1982 and 1989, suggesting that extreme years may not be distributed in a completely random way. IWR were higher in 2003 and 2009 than in 1983, 1985, 1986 and 1989. This may indicate a trend towards intensification of extreme years as a consequence of higher temperatures and increased evaporative demand. However, given the large inter-annual variability across the 30 -year period considered, no statistically significant trend in catchment-scale IWR could be identified, confirming the findings in [12]. A thorough investigation of decadal variations in the precipitation regime is needed to better understand trends in the occurrence of extreme conditions.

In 2003, a record-breaking heat-wave [10,29] struck Western Europe and the Alpine region during summer, leading to a severe precipitation anomaly [14]. Our estimate of the 2003 anomaly in IWR at catchment scale (65\%) was obtained comparing the year 2003 with the 1981-2009 average. In [4,11], the 2003 anomaly in IWR was computed comparing it to IWR for a relatively wet year, respectively 2002 and 1997. Considering only maize, our estimate of the 2003 anomaly is of $68 \%$ in the Rhone catchment. Since 2002 appears to be a year much below average in terms of IWR in the Rhone catchment, the anomaly for maize would be of $\sim 100 \%$ if computed comparing 2003 with 2002 as in [4], who found a 53\% increase in irrigation intensity of maize in France in 2003. In the Okanagan Basin, a $40 \%$ greater irrigation water requirement was estimated and fruit trees found to be most sensitive to increasing demand during dry years [11]. It is also the case in our results for the Rhone catchment, where the 2003 anomaly is of $86 \%$ for apple.

Although we were able to provide a detailed spatial and temporal picture of IWR in an Alpine river catchment that is within the range of previous estimates [12,13], our analysis suffers from the various following limitations that need to be addressed in future work. In the first place, we could not provide a direct validation of the simulated water fluxes against measurements of evaporation rates, precipitation and changes in soil water storage at the local scale. This is not only a problem with the present study, but is valid also for the analysis conducted, e.g., in [12]. Furthermore, we did not quantify uncertainties in computed IWR in a systematic way. Sources of uncertainty are errors in input data (gridded weather fields, land use and soil maps), assumptions related to the daily point-scale model, irrigation target thresholds, site selection for calibration, and exclusion of surface areas with 
critically shallow soils. Based on the model verification at six additional sites (Section 4.1), the uncertainty associated with the simplifications introduced by Equations (11-13) is estimated to be at least $40 \%$ (relative RMSE). However, this figure likely represents a lower estimate of the total uncertainty, as we did not account for issues related to irrigation efficiency, effects of glaciers and snow cover in the seasonal availability of water resources, or effects of the water table fluctuations and the contribution of capillary rise to the water budget of the root zone.

\section{Conclusions}

This paper presents a simple modeling approach for estimating the spatial pattern as well as inter-annual variability of net IWR at the catchment scale. Irrigation requirements are examined in the light of crop water demand, without considering the availability of water for abstraction. The approach accounts for effects of pedo-climatic conditions and crop characteristics, all being particularly heterogeneous in the Swiss Rhone basin.

The three main findings were that: (i) results are within the range of estimates obtained in the application of a process-based, spatially distributed hydrological model and the evaluation of a field survey, which lends some support to the approach; (ii) half of the total potential IWR was found to originate from elevations above $1500 \mathrm{~m}$, where grasslands dominate the non-forested area; (iii) although grasslands are more sensitive to water deficiency and grow mostly on soils that are more shallow than those used for other crop types in this catchment, the wetter climate found at higher elevations compensates for this effect.

In spite of its limitations, the proposed modeling approach seems suitable for exploring implications for the regional agricultural water balance of multiple climate and land use change scenarios, or to identify future trends in IWR at catchment scale. Such applications would help to validate the estimated $22 \%$ increase in IWR expected by the Valais cantonal authority as a consequence of climate and future management changes [13]. Risks from water shortage at the seasonal and local scale are likely to become more important in the future, particularly in view of the drastic decrease in glacier volume and snow cover. This will not only affect agriculture, but other sectors of relevance for the regional economy, including energy production and tourism. By contrasting IWR with the needs from other economic sectors, the proposed methodology can help to identify emerging water conflicts.

\section{Acknowledgments}

This work was supported with grants from the EU-FP7 ACQWA Project and Swiss National Science Foundation through the National Centre for Competence in Research (NCCR) Climate, project AGRISK. We thank the Swiss Federal Office of Meteorology and Climatology (MeteoSwiss) for granting access to its database. Gridded meteorological data were kindly provided by K. Jasper. We acknowledge the use of computing facilities at University of Graz.

\section{References}

1. United Nations Environment Programme (UNEP). Global Environmental Outlook 2000; Earthscan: London, UK, 1999. 
2. Shiklomanov, I.A. Assessment of water resources and water availability in the world. In $U N$ Report: Comprehensive Assessment of the Freshwater Resources of the World; Stockholm Environment Institute: Stockholm, Sweden, 1997.

3. Wriedt, G.; van der Velde, M.; Aloe, A.; Bouraoui, F. A European irrigation map for spatially distributed agricultural modelling. Agric. Water Manag. 2009, 96, 771-789.

4. Van der Velde, M.; Wriedt, G.; Bouraoui, F. Estimating irrigation use and effects on maize yield during the 2003 heatwave in France. Agric. Ecosyst. Environ. 2010, 135, 90-97.

5. Thenkabail, P.S.; Biradar, C.M.; Turral, H.; Noojipady, P.; Li, Y.J.; Vithanage, J.; Dheeravath, V.; Velpuri, M.; Schull, M.; Cai, X.L.; Dutta, R.. An Irrigated Area Map of the World (1999) Derived from Remote Sensing; Research Report No. 105; International Water Management Institute: Colombo, Sri Lanka, 2006.

6. Siebert, S. Global Map of Irrigation Areas Version 4.0.1.; Food and Agriculture Organization of the United Nations (FAO): Rome, Italy, 2007. Available online http:/www.fao.org/nr/water/ aquastat/quickWMS/irrimap.htm (accessed on 21 July 2012).

7. Döll, P.; Siebert, S. Global modelling of irrigation water requirements. Water Resour. Res. 2002, 38, 8:1-8:10.

8. Wriedt, G.; van der Velde, M.; Aloe, A.; Bouraoui, F. Estimating Irrigation water requirements in Europe. J. Hydrol. 2009, 373, 527-544.

9. Allen, R.G.; Pereira, L.S.; Raes, D.; Smith, M. Crop Evapotranspiration: Guidelines for Computing Crop Water Requirements; FAO Irrigation and Drainage Paper 56; Food and Agriculture Organization of the United Nations (FAO): Rome, Italy, 1998.

10. ACQWA EU-FP7 Project (Assessing Climate impacts on the Quantity and quality of Water, Seventh Research Framework Programme). Available online: http://www.acqwa.ch (accessed on 1 November 2012).

11. Schreier, H.; Lavkulich, L.; Brown, L. Real and Virtual Water and Water Footprints: A Comparison between the Lower Fraser Valley and the Okanagan Basin; Technical Report For Walter and Duncan Gordon Foundation: Toronto, Canada, 2007.

12. Fuhrer, J.; Jasper, K. Demand and supply of water for agriculture: Influence of topography and climate in pre-alpine, mesoscale catchments. Nat. Resour. 2012, 3, 145-155.

13. Weber, M.; Schild, A. Stand der Bewässerung in der Schweiz (in German); Bericht zur Umfrage 2006-Report; Federal Office of Agriculture: Bern, Switzerland, 2007.

14. Weingartner, R.; Viviroli, D.; Schädler, B. Water resources in mountain regions: a methodological approach to assess the water balance in a highland-lowland system. Hydrol. Process. 2007, 21, $578-585$.

15. Huss, M. Present and future contribution of glacier storage change to runoff from macroscale drainage basins in Europe. Water Resour. Res. 2011, 47, W07511:1-W07511:14.

16. MeteoSwiss Norm Values. Available online: http://www.meteoswiss.admin.ch/web/de/klima/ klima_schweiz/tabellen.Par.0011.DownloadFile.ext.tmp/niederschlagssummen.pdf (accessed on 21 July 2012).

17. Swiss Federal Statistical Office. Bodennutzung im Wandel: Arealstatistik der Schweiz (in German); Swiss Federal Statistical Office: Neuchâtel, Switzerland, 2001. 
18. Swiss Federal Statistical Office. Digital Map of the Soil Aptitudes; Swiss Federal Statistical Office: Neufchâtel, Switzerland, 2004.

19. Schulla, J. Hydrologische Modellierung von Fluss-gebieten zur Abschätzung der Folgen von Klimaänderungen (in German), 1997; dx.doi.org/10.3929/ethz-a-001763261; ETH E-Collection. Available online: http://e-collection.library.ethz.ch/view/eth:40649 (accessed on 1 November 2012).

20. Schulla, J.; Jasper, K. WASIM-ETH Model Documentation. Available online: http://www.wasim.ch/downloads/doku/wasim/interpolation_meteodata_2009_en.pdf (accessed on 21 July 2012).

21. Davies, J.A. A note on the relationship between net radiation and solar radiation. Quart. J. R. Meteorol. Soc. 1967, 93, 109-115.

22. Office d'arboriculture du Valais. Gestion de l'irrigation en Arboriculture-Rapport Annuel 2008 (in French); Département de l'économie et du Territoire, Service Cantonal d'agriculture: Sion, France, 2008.

23. Goodwin, I. Irrigation of Vineyards; Institute of Sustainable Agriculture: Victoria, Tatura, Australia, 1995.

24. Lazzarotto, P.; Calanca, P.; Fuhrer, J. Dynamics of grass-clover mixtures-An analysis of the response to management with the PROductive GRASsland Simulator (PROGRASS). Ecol. Model. 2009, 220, 703-724.

25. Brisson, N.; Ruget, F.; Gate, P.; Lorgeou, J.; Nicoullaud, B.; Tayot, X.; Plenet, D.; Jeuffroy, M.H.; Bouthier, A.; Ripoche, D. STICS: A generic model for simulating crops and their water and nitrogen balances. II. Model validation for wheat and maize. Agronomie 2002, 22, 69-92.

26. Boland, A.-M.; Bewsell, D.; Kaine, G. Adoption of sustainable irrigation management practices by stone and pome fruit growers in the Goulburn/Murray Valleys, Australia. Irrig. Sci. 2006, 24, $137-145$.

27. Bravin, E.; Hofmann, M.D.; Monney, P. Klimaveränderung: Welche Zunahme der Bewässerungskosten in der Apfelproduktion ist tragbar (in German). Schweiz. Ges. Agrarwirtsch. Agrarsoziol. 2008, 133-160. Available online: www.volkskunde.ch/dms/agrarwirtschaft/ Internetseite/Yearbook/Ausgaben/Yearbook-2008/06_Bravin_neu-_4_/Esther-Bravin.pdf (accessed on 1 November 2012).

28. Zurwerra, R. Die Wiesebbewässerung im Wallis-Zwischen tradition und moderne (in German). Géomat. Suisse 2010, 10, 454-457.

29. Schär, C.; Vidale, P.L.; Lüthi, D.; Frei, C.; Häberli, C.; Liniger, M.A.; Appenzeller, C. The role of increasing temperature variability in European summer heatwaves. Nature 2004, 427, 332-336.

(C) 2012 by the authors; licensee MDPI, Basel, Switzerland. This article is an open access article distributed under the terms and conditions of the Creative Commons Attribution license (http://creativecommons.org/licenses/by/3.0/). 